\title{
Effects of low level exposure to lead on neurophysiological functions among lead battery workers
}

Tero Kovala, Esko Matikainen, Tarmo Mannelin, Jari Erkkilä, Vesa Riihimäki, Helena Hänninen, Antero Aitio

\begin{abstract}
Objectives-Assessment of neurophysiological functions in workers with low level exposure to lead and evaluation of the efficacy of bone lead measurements in the prediction of effects of lead.

Methods-Exposure to lead of 60 workers from a lead battery factory was estimated from historical blood lead measurements and analysis of lead in the tibial and calcaneal bones with $x$ ray fluorescence. Peripheral and central nervous system functions were assessed by measuring conduction velocities, sensory distal latencies, sensory amplitudes, and vibration thresholds as well as by quantitative measurement of the absolute and relative powers and mean frequencies of different electroencephalograph (EEG) channels.

Results-Sensory amplitudes, and to a smaller degree sensory or motor conduction velocities, showed a negative correlation with long term exposure to lead, most clearly with integrated blood lead concentration and exposure time. Vibration thresholds measured in the arm were related to recent exposure to lead, those measured in the leg to long term exposure. The alpha and beta activities of the EEG were more abundant in subjects with higher long term exposure to lead. Calcaneal lead content reflected short term exposure, tibial lead content reflected long term exposure. Blood lead history showed a closer relation with effects of lead than the tibial or calcaneal lead concentrations.
\end{abstract}

Conclusions-Vibratory thresholds, quantitative EEG, and to a smaller extent the sensory amplitude, provide sensitive measures of effects of lead in occupationally exposed adults. Most accurate estimates of health risks induced by lead can be obtained from a good history of blood lead measurements. If such a history of blood lead concentrations is not available, analysis of bone lead may be used for the assessment of health risks.

(Occup Environ Med 1997;54:487-493)

Keywords: $x$ ray fluorescence; bone lead; blood lead; quantitative EEG; conduction velocity; vibratory threshold
The nervous system is the major target of lead toxicity. In the Nordic countries, overt lead intoxications are rare. In Finland, there have been no clinical intoxications for many years. However, blood lead (B-Pb) concentrations above the limit value $(2.4 \mu \mathrm{mol} / \mathrm{l})$ still occur in Finland.

During the past 20 years, there have been many reports showing that abnormalities in the function of the peripheral nervous system may also occur with low $\mathrm{B}-\mathrm{Pb}$ concentrations, in symptom free workers. $^{12}$ In a two year prospective follow up study, the motor and sensory conduction velocity of the median nerve was found to be less in car battery workers, with a B-Pb concentration $>30 \mu \mathrm{g} / 100 \mathrm{ml}$ $(1.5 \mu \mathrm{mol} / \mathrm{l})$ than in similar workers with a $\mathrm{B}-\mathrm{Pb}$ concentration $<30 \mu \mathrm{g} / 100 \mathrm{ml}^{3}$ There are, however, also studies, in which no alterations in conduction velocities could be found with $\mathrm{B}-\mathrm{Pb}$ concentrations $<70 \mu \mathrm{g} / 100 \mathrm{ml}$ (3.4 $\mu \mathrm{mol} / \mathrm{l}) .^{45}$

In vivo $x$ ray fluorescence has recently been added to the methods of assessment of body burden of lead (body- $\mathrm{Pb}$ ); at present these methods are capable of accurately assessing the bone lead contents in occupationally nonexposed people, even children..$^{6-8}$

The objective of this study was to evaluate the effects on neurophysiological functions of the current, low levels of exposure to lead, and the effects of past higher exposure (also comparatively low), the potential of the bone analysis with $x$ ray fluorescence in the assessment of body- $\mathrm{Pb}$, and its relation with the functions of the nervous system. We have also analysed the effects of lead on neuropsychological functions in these workers (unpublished data).

\section{Subjects and methods}

SUBJECTS

Altogether 48 men and 12 women working in two acid battery factories were studied. Their mean (SD, range) age was $43(9,22-60)$ years, the duration of exposure $16(8,1-42)$ years, and the actual $\mathrm{B}-\mathrm{Pb}$ concentration, $1.3(0.4$, $0.7-2.5) \mu \mathrm{mol} / 1$.

BODY BURDEN OF LEAD

The body- $\mathrm{Pb}$ was estimated by measuring the concentration of both tibial lead and calcaneal lead by $x$ ray fluorescence. ${ }^{6-8}$ Exposure to lead was also measured from $\mathrm{B}-\mathrm{Pb}$ concentrations covering the whole duration of the exposure. 
Table 1 Characteristics of the studied population

\begin{tabular}{lllllll}
\hline & Unit & $n$ & Median & Mean & $S D$ & Range \\
\hline Tibial lead & $\mathrm{mg} / \mathrm{kg}$ & 59 & 23 & 26 & 17 & -4 to 65 \\
Calcaneal lead & $\mathrm{mg} / \mathrm{kg}$ & 59 & 78 & 88 & 54 & -4 to 234 \\
Body- $\mathrm{Pb}$ & $\mathrm{mg}$ & 58 & 94 & 103 & 54 & 6 to 210 \\
$\mathrm{~B}^{-} \mathrm{Pb}_{\text {int }}$ & $\mu \mathrm{mol} / 1 \times \mathrm{y}$ & 56 & 23 & 26 & 19 & 0.7 to 104 \\
$\mathrm{~B}_{\mathrm{Pb}}$ & $\mu \mathrm{mol} / 1$ & 58 & 1.5 & 1.6 & 0.4 & 0.7 to 2.5 \\
$\mathrm{~B}-\mathrm{Pb}_{\text {max }}$ & $\mu \mathrm{mol} / 1$ & 59 & 2.4 & 2.5 & 0.9 & 0.9 to 4.9 \\
$\mathrm{~B}-\mathrm{Pb}_{\text {int3 }}$ & $\mu \mathrm{mol} / 1 \times \mathrm{y}$ & 57 & 4.2 & 4.1 & 1.4 & 0.7 to 6.6 \\
$\mathrm{~B}-\mathrm{Pb}$ av3 & $\mu \mathrm{mol} / 1$ & 57 & 1.4 & 1.4 & 0.4 & 0.6 to 2.2 \\
$\mathrm{~B}-\mathrm{Pb}$ max 3 & $\mu \mathrm{mol} / 1$ & 57 & 1.7 & 1.7 & 0.5 & 0.7 to 2.8 \\
$\mathrm{~B}-\mathrm{Pb}$ & $\mu \mathrm{mol} / 1$ & 58 & 1.3 & 1.3 & 0.4 & 0.5 to 2.2 \\
Duration of exposure & $\mathrm{y}$ & 60 & 17 & 16 & 8 & 1 to 42 \\
Age & $\mathrm{y}$ & 60 & 43 & 43 & 9 & 22 to 60 \\
\hline
\end{tabular}

$\mathrm{B}-\mathrm{Pb}=$ integrated blood lead concentration; $\mathrm{B}-\mathrm{Pb}_{\mathrm{av}}=$ time weighted average blood concentration; $\mathrm{B}-\mathrm{Pb}_{\max }=$ maximal blood lead concentration ever recorded; $\mathrm{B}-\mathrm{Pb}_{\mathrm{int} 3}=$ integrated blood lead concentration during the past three years; $\mathrm{B}-\mathrm{Pb}_{\text {ave } 3}=$ time weighted average blood lead concentration over the past three years; $\mathbf{B}-\mathrm{Pb}_{\max 3}=$ maximal blood lead concentration during the past three years; $\mathrm{B}-\mathrm{PB}_{\mathrm{B}}=$ actual blood lead concentration.

The mean (SD) number of lead measurements per person was 32 (30) and the interval between successive measurements 109 (70) days. All $\mathrm{B}-\mathrm{Pb}$ measurements were performed in one laboratory, which has a good record in external quality assurance schemes.

The exposure was described by the following variables: calcaneal lead, tibial lead, body- $\mathrm{Pb}$ as calculated from the weighted sum of calcaneal and tibial lead $(2.2 \times$ tibial lead $+0.5 \times$ calcaneal lead), actual $\mathrm{B}-\mathrm{Pb}$ concentration, $\mathrm{B}-\mathrm{Pb}$ concentration integrated over the time of exposure, time weighted average $\mathrm{B}-\mathrm{Pb}$ concentration, and the highest measured $\mathrm{B}-\mathrm{Pb}$ concentration. ${ }^{8}$ To describe the more recent exposure, the mean, maximal, and time integrated cumulative $\mathrm{B}-\mathrm{Pb}$ concentrations for the past three years, were also calculated.

\section{CONDUCTION STUDIES}

The following conduction variables were recorded from each participant: motor conduction velocity, motor distal latency of the right median and deep peroneal nerves, and sensory conduction velocity, sensory distal latency, and sensory amplitude of the right median, radial, and sural nerves. $\mathrm{H}$ reflex latencies were measured from the posterior tibial nerves. The median nerve sensory studies were performed orthodromically, the others antidromically. Surface electrodes were used for recording, for stimulation a Disa felt pad electrode was used. The temperatures of the limbs were measured, and if below $31^{\circ} \mathrm{C}$, the limbs were warmed. The distance between the stimulation and recording electrodes was constant for all recordings. A supramaximal $0.2 \mathrm{~ms}$ square wave stimulation was applied on the nerve, except in $\mathbf{H}$ reflex studies, where the duration of the stimulation was $0.5 \mathrm{~ms}$. The sensory amplitudes were measured from the base line to the peak.

VIBRATORY THRESHOLDS

The vibratory thresholds were measured with a VIBRA MKII device. The thresholds were measured with both the method of limits and the forced choice method. ${ }^{9}$ The sites used in the measurements were the dorsal side of the distal phalanx of the left forefinger, the second metacarpophalangeal joint, and the medial malleolus in the ankle. The vibrator rested on the limb with a weight of $100 \mathrm{~g}$. Three measurements were performed with the methods of limits, and the mean was used as the vibratory threshold.

\section{QUANTITATIVE EEG}

The EEG was recorded on 21 channels with a $70 \mathrm{~Hz}$ low pass filter and a $50 \mathrm{~Hz}$ notch filter. The sampling frequency of the $\mathrm{A} / \mathrm{D}$ transformation was $205 \mathrm{~Hz}$. The signals were stored on an optical disc, and the analyses were performed later off line. In each recording, $60 \mathrm{~s}$ artefact free waking activity (24 epochs lasting $2.5 \mathrm{~s}$ each) was selected visually for spectral analysis. Eight recordings had to be abandoned because 24 epochs fulfilling the criteria could not be found. The absolute and relative powers as well as the mean frequencies of the delta $(1.5-3.5 \mathrm{~Hz})$, theta $(3.5-7.5 \mathrm{~Hz})$, alpha $(7.5-$ $12.5 \mathrm{~Hz})$ and beta $(12.5-20.0 \mathrm{~Hz})$ bands, and the mean frequencies within the whole 1.5$20 \mathrm{~Hz}$ frequency band were computed from all channels. The number of variables was reduced by calculating regional means from the original variables: frontal region (Fp1, Fp2, F3, F4, Fz, and $\mathrm{Fpz}$ ), temporal region (T3, T4, T5, and T6), centroparietal region (C3, C4, Cz, P3, P4, and $\mathrm{Pz}$ ), and occipital region $(\mathrm{O} 1, \mathrm{O} 2$, and $\mathrm{Oz}$ ). After these calculations there remained 52 EEG variables (16 for the absolute power, 16 for the relative power, and 20 for mean frequencies).

\section{STATISTICAL ANALYSES}

The SAS statistical software was used in the data analysis. The coefficients of correlation were calculated with the Spearman rank correlation analysis. The results of peripheral nerve function were treated by partial correlation and regression analyses, taking age into account. Differences between groups were tested by Wilcoxon rank sum test.

\section{Results}

BODY BURDEN OF LEAD

Mean concentrations were $26 \mathrm{mg} / \mathrm{kg}$ for tibial lead and $88 \mathrm{mg} / \mathrm{kg}$ for calcaneal lead (table 1 ). The calculated mean body- $\mathrm{Pb}$ was $103 \mathrm{mg}$. Mean long term $\mathrm{B}-\mathrm{Pb}$ content was $1.6 \mu \mathrm{mol} / \mathrm{l}$, mean maximal $\mathrm{B}-\mathrm{Pb} 2.5 \mu \mathrm{mol} / \mathrm{l}$, and highest recorded $\mathrm{B}-\mathrm{Pb}, 4.9 \mu \mathrm{mol} / \mathrm{l}$. During the past three years, the corresponding figures were 1.4 , 1.7 , and $2.8 \mu \mathrm{mol} / 1$.

Variables reflecting long term exposure: tibial lead, body- $\mathrm{Pb}$, mean $\mathrm{B}-\mathrm{Pb}$, and integrated $\mathrm{B}-\mathrm{Pb}$ were strongly correlated with each other (table 2). Maximal B-Pb measured was also strongly correlated with all these variables. Tibial lead, body- $\mathrm{Pb}$, integrated $\mathrm{B}-\mathrm{Pb}$, mean $\mathrm{B}-\mathrm{Pb}$, and maximal $\mathrm{B}-\mathrm{Pb}$ were strongly correlated with duration of exposure, but less obviously with age. Tibial lead was not related to variables reflecting exposure over the past three years.

Calcaneal lead correlated with both long and short term exposure variables. Variables reflecting short term exposure, including the actual $\mathrm{B}-\mathrm{Pb}$ concentration, were strongly correlated with each other and with the long term mean and maximal $\mathrm{B}-\mathrm{Pb}$ concentrations, but 
Table 2 Correlations between different variables reflecting exposure and body-Pb

\begin{tabular}{|c|c|c|c|c|c|c|c|c|c|c|c|}
\hline & $\begin{array}{l}\text { Calcaneal } \\
\text { lead }\end{array}$ & $B o d y-P b$ & $B-P b_{i m}$ & $B-P b_{a v}$ & $B-P b_{\max }$ & $B-P b_{i n t 3}$ & $B-P b_{a x t 3}$ & $B-P b_{\max 3}$ & $B-P b$ & $\begin{array}{l}\text { Duration of } \\
\text { exposure }\end{array}$ & Age \\
\hline $\begin{array}{l}\text { Tibial lead } \\
\text { Calcaneal lead } \\
\text { Body-Pb } \\
\text { B-Pb } \\
\mathrm{B}_{\text {int }} \\
\mathrm{B}-\mathrm{Pb}_{\mathrm{av}} \\
\mathrm{B}-\mathrm{Pb}_{\max } \\
\mathrm{B}-\mathrm{Pb}_{\text {ave } 3} \\
\mathrm{~B}-\mathrm{Pb} \text { max } 3 \\
\mathrm{~B}-\mathrm{Pb} \\
\text { Duration of exposure }\end{array}$ & $0.45^{\star \star \star}$ & $\begin{array}{l}0.89^{\star \star \star} \\
0.79^{\star \star \star}\end{array}$ & $\begin{array}{l}0.64^{\star \star \star} \\
0.35^{\star \star} \\
0.61^{\star \star \star}\end{array}$ & $\begin{array}{l}0.45^{\star \star \star} \\
0.55^{\star \star \star} \\
0.60^{\star \star \star} \\
0.66^{\star \star \star}\end{array}$ & $\begin{array}{l}0.57^{\star \star \star} \\
0.50^{\star \star \star} \\
0.64^{\star \star \star} \\
0.82^{\star \star \star} \\
0.82^{\star \star \star}\end{array}$ & $\begin{array}{l}0.14 \\
0.47^{\star \star \star} \\
0.36^{\star \star} \\
0.39^{\star \star} \\
0.80^{\star \star \star} \\
0.50^{\star \star \star}\end{array}$ & $\begin{array}{l}0.15 \\
0.51^{\star \star \star} \\
0.38^{\star \star} \\
0.31^{\star \star} \\
0.79^{\star \star \star} \\
0.51^{\star \star \star} \\
0.95^{\star \star \star}\end{array}$ & $\begin{array}{l}0.14 \\
0.56^{\star \star \star} \\
0.39^{\star \star} \\
0.24 \dagger \\
0.71^{\star \star \star} \\
0.48^{\star \star \star} \\
0.88^{\star \star \star} \\
0.96^{\star \star \star}\end{array}$ & $\begin{array}{l}0.25^{\star} \\
0.48^{\star \star \star} \\
0.42^{\star \star} \\
0.26^{\star} \\
0.73^{\star \star \star} \\
0.48^{\star \star \star} \\
0.85^{\star \star \star} \\
0.93^{\star \star \star} \\
0.88^{\star \star \star}\end{array}$ & $\begin{array}{l}0.59^{\star \star \star} \\
0.20 \\
0.49^{\star \star \star} \\
0.91^{\star \star \star} \\
0.43^{\star \star \star} \\
0.64^{\star \star \star} \\
0.08 \\
-0.03 \\
-0.09 \\
-0.05\end{array}$ & $\begin{array}{l}0.37^{\star \star} \\
-0.19 \\
0.21 \dagger \\
0.57^{\star \star \star} \\
0.14 \\
0.39^{\star \star} \\
-0.10 \\
-0.19 \\
-0.25 \dagger \\
-0.21 \dagger \\
0.64^{\star \star \star}\end{array}$ \\
\hline
\end{tabular}

${ }^{\star} \mathrm{P}<0.05 ;{ }^{\star \star} \mathrm{P}<0.01 ;{ }^{\star \star \star} \mathrm{P}<0.001 ;+\mathrm{P}<0.1$.

Abbreviations as for table 1 .

not with time of exposure or long term integrated $\mathrm{B}-\mathrm{Pb}$.

\section{NEUROPHYSIOLOGICAL STUDIES}

Compared with the reference values used in the laboratory for clinical diagnostic studies, abnormal conduction variables were found in six cases. In two subjects, the results suggested a chronic lumbar radicular disorder ( $\mathrm{H}$ reflex). In two others, there was a local slowing of the conduction velocity of the median nerve, probably caused by an entrapment neuropathy. In the remaining two, the findings suggested a slight polyneuropathy. The mean values of the conduction velocity variables of the whole group were within normal limits.

A slight decrease in vibratory sensibility in the leg was found in 12 people. In one case the decrease was considerable, in the others it was marginal. There were no clinical abnormalities in the vibratory perception in the arms. The means of the vibratory threshold were within the normal limits of our laboratory.

AMPLITUDES AND CONDUCTION VELOCITIES

There were weak negative correlations between indicators of exposure to lead and the conduction velocities and sensory amplitudes of the median, radial, peroneal, and sural nerves, but most of them did not reach significance. Table 3 shows the measurements for which significant correlations were found.

The conduction velocity of the median nerve correlated weakly (negatively) with tibial lead $(\mathrm{P}<0.1)$, body- $\mathrm{Pb}(\mathrm{P}<0.1)$, and more strongly $(P<0.05)$ with age (table 3$)$. After controlling for the effect of age, the effect of tibial lead concentration was non-significant.

There was a significant negative correlation between the sensory amplitude of the sural nerve and the integrated $\mathrm{B}-\mathrm{Pb}$ concentration, duration of exposure, tibial lead content, and calculated body- $\mathrm{Pb}$; no such correlation was found for the radial nerve; the correlation between maximal $\mathrm{B}-\mathrm{Pb}$ concentration and sural amplitude was of borderline significance. The sural nerve sensory amplitude was lower $(17.0, \mathrm{SD} 8.2 \mu \mathrm{V})$ in workers with at least one $\mathrm{B}-\mathrm{Pb}$ measurement $>2.4 \mu \mathrm{mol} / 1$ than in the group in which the $\mathrm{B}-\mathrm{Pb}$ never exceeded this value $(23.3, \mathrm{SD} 11.9 \mu \mathrm{V}, \mathrm{P}<0.05)$. The sensory amplitude of the median nerve showed a negative correlation with integrated $\mathrm{B}-\mathrm{Pb}$ content, and duration of exposure, and was not significantly related to variables reflecting exposure over the past three years, or age.

\section{VIBRATORY THRESHOLDS}

The vibration thresholds correlated with age $(0.21<r<0.53)$; therefore, partial Spearman correlation coefficients were calculated after controlling for the effect of age (table 4).

The finger threshold, measured with the method of limits, correlated significantly with all variables of recent exposure, including the calcaneal lead content. With the forced choice method these correlations were weaker and remained statistically not significant. The correlations between the finger threshold and variables reflecting long term exposure were weaker, and reached significance $(P<0.05)$ only for body- $\mathrm{Pb}$. The vibratory threshold of the metacarpophalangeal joint weakly related to exposure during the past three years, but only approached significance $(P<0.1)$ for calcaneal lead, and mean and maximal three year $\mathrm{B}-\mathrm{Pb}$ concentration. However, the vibratory threshold of the metacarpophalangeal joint was significantly higher in the group with the maximal $\mathrm{B}-\mathrm{Pb}>2.4 \mu \mathrm{mol} / \mathrm{l}$ than in the group with the lower maximal B-Pb (0.70 (SD $0.52) v 0.47$ (SD 0.20), $\mathrm{P}<0.05)$. Similarly, the threshold was also higher in the ankle (3.8 (SD 5.1) $v 2.2$ (SD 2.5)), but the difference was not significant. Those workers with three year time integrated $\mathrm{B}-\mathrm{Pb} \geqslant 4.0$ had higher vibratory

Table 3 Spearman rank correlation coefficients between the peripheral nervous system measurements and the exposure variables

\begin{tabular}{|c|c|c|c|c|c|c|c|c|}
\hline & $\begin{array}{l}\text { Tibial } \\
\text { lead }\end{array}$ & $\begin{array}{l}\text { Calcaneal } \\
\text { lead }\end{array}$ & $B o d y-P b$ & $B-P b_{i n t}$ & $B-P b_{\text {are }}$ & $B-P b_{\max }$ & $\begin{array}{l}\text { Duration of } \\
\text { exposure }\end{array}$ & Age \\
\hline MCV, median nerve & $-0.23 t$ & -0.16 & $-0.23 t$ & -0.17 & 0.03 & -0.11 & -0.18 & $-0.30^{\star}$ \\
\hline SCV, sural nerve & -0.08 & -0.18 & -0.12 & -0.21 & -0.01 & -0.19 & $-0.26^{\star}$ & -0.01 \\
\hline Amplitude, median nerve & -0.10 & 0.03 & -0.09 & $-0.34^{\star}$ & -0.04 & -0.08 & $-0.29^{\star}$ & -0.16 \\
\hline Amplitude, sural nerve & $-0.31^{\star}$ & -0.12 & $-0.32^{\star}$ & $-0.40^{\star \star}$ & -0.10 & $-0.25 t$ & $-0.36^{\star \star}$ & -0.21 \\
\hline
\end{tabular}

$\star \mathrm{P}>0.05 ; \star \star \mathrm{P}<0.01 ;+\mathrm{P}<0.1$.

$\mathrm{MCV}=$ motor conduction velocity; $\mathrm{SCV}=$ sensory conduction velocity.

Other abbreviations as for table 1 . 
Table 4 Partial Spearman rank correlation coefficients between the vibratory thresholds and the exposure variables after removing the effect of age

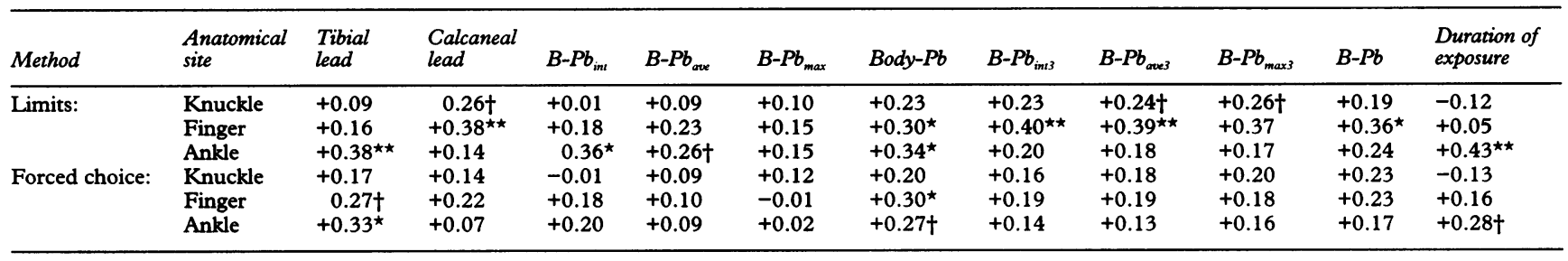

$\star \mathrm{P}<0.05 ; \star \star \mathrm{P}<0.01 ;+\mathrm{P}<0.1$.

Knuckle $=2$ nd metacarpophalangeal joint; finger $=$ index finger; ankle: medial malleolus.

Other abbreviations as for table 1 .

thresholds in the fingers than those with three year time integrated $\mathrm{B}-\mathrm{Pb}<4.0(0.9$ (SD 0.5), $v 0.7$ (SD 0.5), $\mathrm{P}<0.05$ ).

The malleolar threshold correlated with variables that reflected long term exposure, including the tibial lead content as well as exposure duration; this effect was also most pronounced when the limit method was used; it did not completely disappear when the forced choice method was used.

\section{QUANTITATIVE EEG}

The large amount of data from the quantitative EEG were reduced by combining individual data points to means representing larger brain areas - namely, the frontal, temporal, centroparietal, and occipital regions. Qualitatively similar results were obtained for all regions, but the correlations were most significant in the frontal, central, and temporal regions of the head. Table 5 shows the data for the frontal region for those exposure variables for which significant relations were found.

The absolute power of the beta band correlated significantly with the descriptors of long term exposure, the correlation reached significance for integrated, mean, and maximal long term $\mathrm{B}-\mathrm{Pb}$ concentration, but not for tibial lead content or body- $\mathrm{Pb}$. The relative beta power was weakly $(P<0.1)$ related to integrated $\mathrm{B}-\mathrm{Pb}$ concentration, but not to other variables that reflected long or short term exposure.

The absolute and relative power of the alpha band were related to mean long term $\mathrm{B}-\mathrm{Pb}$, but only weakly to other variables of long term exposure. Conversely, it was also related to calcaneal lead content. The mean frequency of the alpha band showed a negative correlation with all descriptors of exposure to lead, most

Table 5 Spearman rank correlation between power values and mean frequencies in the frontal region with measures of lead exposure and body-Pb

\begin{tabular}{|c|c|c|c|c|c|c|}
\hline $\begin{array}{l}\text { Quantitative EEG } \\
\text { variable }\end{array}$ & Tibial lead & $\begin{array}{l}\text { Calcaneal } \\
\text { lead }\end{array}$ & $B o d y-P b$ & $B-P b_{i n t}$ & $B-P b_{a v e}$ & $B-P b_{\text {max }}$ \\
\hline \multicolumn{7}{|l|}{ Absolute power: } \\
\hline Delta band & 0.04 & 0.17 & 0.07 & -0.06 & 0.10 & -0.02 \\
\hline Theta band & 0.06 & -0.03 & -0.01 & -0.09 & 0.004 & -0.01 \\
\hline Alpha band & 0.11 & $0.33^{\star}$ & 0.23 & 0.09 & $0.36^{\star}$ & 0.15 \\
\hline Beta band & 0.22 & 0.08 & 0.16 & $0.37^{\star \star}$ & $0.28^{\star}$ & $0.31^{\star}$ \\
\hline \multicolumn{7}{|l|}{ Relative power: } \\
\hline Delta band & -0.17 & $-0.31^{\star}$ & $-0.26 t$ & -0.20 & $-0.40^{\star \star}$ & -0.22 \\
\hline Theta band & -0.11 & $-0.35^{\star}$ & $-0.26 \dagger$ & $-0.26 \dagger$ & $-0.32^{\star}$ & -0.17 \\
\hline Alpha band & 0.09 & $0.29^{\star}$ & 0.21 & 0.07 & $0.31^{\star}$ & 0.11 \\
\hline Beta band & 0.05 & -0.09 & -0.04 & $0.28 t$ & -0.03 & 0.17 \\
\hline \multicolumn{7}{|l|}{ Mean frequency: } \\
\hline Total $(1.5-20 \mathrm{~Hz})$ & 0.18 & 0.10 & 0.14 & $0.42^{\star \star}$ & 0.23 & $0.26 t$ \\
\hline Alpha band & $-0.42^{\star \star}$ & $-0.33^{\star}$ & $-0.51^{\star \star}$ & -0.10 & $-0.27 t$ & $-0.29^{\star}$ \\
\hline
\end{tabular}

${ }^{\star} \mathrm{P}>0.05 ;{ }^{\star \star} \mathrm{P}<0.01 ;+\mathrm{P}<0.1$

Abbreviations as for table 1 .

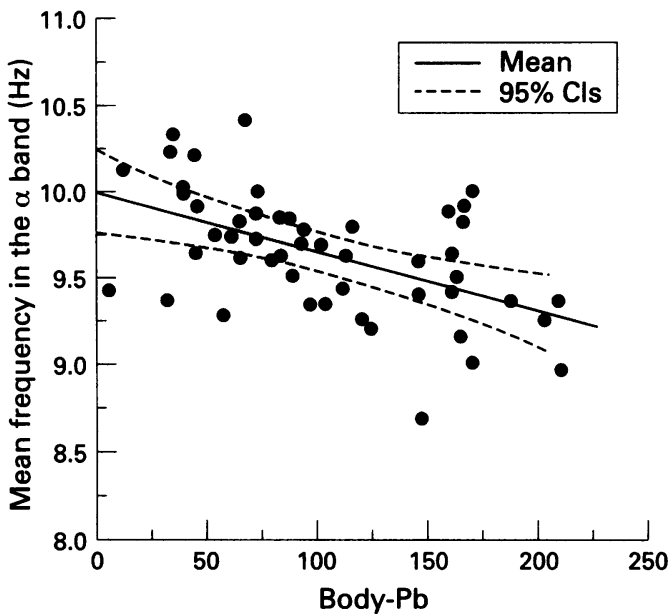

Figure 1 Relation between body-Pb and the mean frequency in the a band of the EEG. The line of the best linear fit, as well as the $95 \%$ CIs of the mean have been indicated.

clearly with body- $\mathrm{Pb}$ (fig 1 ) and its components, tibial and calcaneal lead concentrations.

The absolute power of delta and theta bands was not related to exposure to lead, but the relative power in these bands was negatively correlated with descriptors of long term exposure, as well as with calcaneal lead. The correlations reached significance for calcaneal lead and mean long term $\mathrm{B}-\mathrm{Pb}$ concentration.

The total mean frequency of the EEG was correlated with long term integrated $\mathrm{B}-\mathrm{Pb}$ concentration $(P<0.01)$, and less strongly with mean and maximal $\mathrm{B}-\mathrm{Pb}$ concentrations.

\section{RELATIONS BETWEEN PSYCHOLOGICAL AND}

VIBRATORY VARIABLES

The effects of exposure to lead on six broad function areas: reaction speed (visual and auditory simple reaction times), speed of visuomotor function (Santa Ana dexterity test, digit symbol test), visual and visuospatial abilities (block design, embedded figures), visual memory (memory for design, digit symbol retention), verbal comprehension (synonyms, similarities), and verbal memory (digit span, associative learning), were studied (unpublished data). In the present paper, we assess the relations between the psychological test results and neurophysiological findings. Among the people studied, there were seven with six or seven low psychological test scores, and five with four or five low scores. Those with a poor performance in the psychological tests tended also to have higher vibratory thresholds (fig 2). The difference in the metacarpophalangeal joint vibratory thresholds approached 


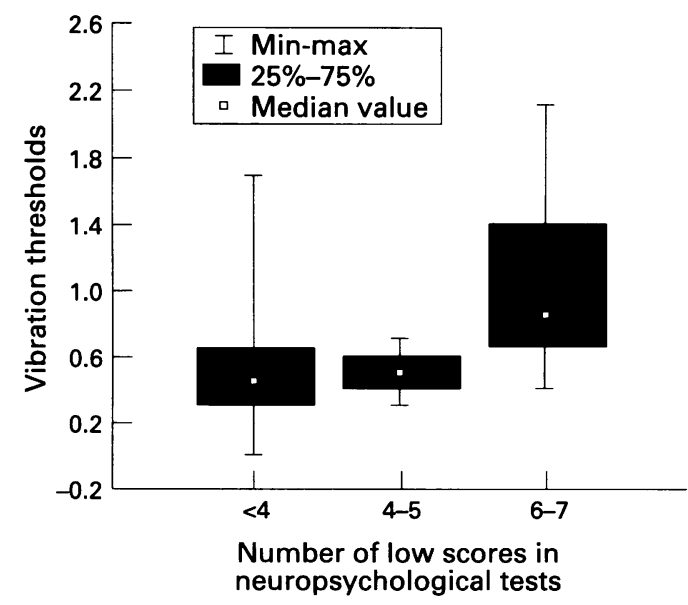

Figure 2 Vibration thresholds of workers with $<4,4-5$, and 6-7 low psychological test scores.

significance $(P<0.1)$ between the groups $(0.52$ $v 0.80$ with the method of limits and $0.28 v$ 0.38 with the force choice method). At the same significance level $(10 \%)$ there was also a difference in the median nerve motor conduction velocity, motor distal latency, and sensory conduction velocity. In relation to the other variables, there were no significant differences.

\section{Discussion}

The effects of occupational exposure to lead on the nervous system have been described in several papers. ${ }^{510-21}$ No unanimity has, however, been reached, on the lowest exposures at which such effects are found. ${ }^{22-24}$

\section{PERIPHERAL NERVOUS SYSTEM}

Abnormalities in the peripheral nervous system have been described even in neurologically asymptomatic workers whose $\mathrm{B}-\mathrm{Pb}$ concentration never exceeded $3.4 \mu \mathrm{mol} / 1,{ }^{2}{ }^{10}$ The most common finding was slowing of the conduction velocity of the median and ulnar nerve, although considerably fewer abnormalities were found in the nerves of the legs. A correlation of several conduction velocities of the arms with time weighted mean lead concentration was found. " Seppäläinen and Hernberg have also shown that the median nerve motor conduction velocity may slow down during follow up among workers with $\mathrm{B}-\mathrm{Pb}$ concentrations $>1.5 \mu \mathrm{mol} / 1 .^{3}$ Contrasting findings have also been presented; Nielsen and coworkers ${ }^{4}$ and Triebig and coworkers ${ }^{5}$ could not show any significant functional changes in the peripheral nervous system with $\mathrm{B}-\mathrm{Pb}$ concentrations $<3.4$ $\mu \mathrm{mol} / 1$.

In the present work, the measurements of the function of the peripheral nervous system were correlated with measurements of bone lead concentration, and with integrated short and long time exposure variables, based on long term information of the $\mathrm{B}-\mathrm{Pb}$ concentrations. $A$ cross sectional evaluation of the $\mathrm{B}-\mathrm{Pb}$ concentration reflects the present exposure, but does not give information of the past exposure, which has been shown to be important for adverse effects. The people working in the car battery factories studied have a long working history. They may have rotated jobs involving different exposures, as indicated by their $\mathrm{B}-\mathrm{Pb}$ concentrations and symptoms. Further, as the limit for $\mathrm{B}-\mathrm{Pb}$ has changed, the actual exposure to lead has likely diminished.

Effects of exposure to lead on vibratory perception have been studied little. Nielsen and coworkers ${ }^{4}$ measured vibratory perception of the hand and foot with a biothesiometer. They did not find any effect of lead on the vibratory perception, even though the average $\mathrm{B}-\mathrm{Pb}$ concentration of the subjects studied was 2.5 $\mu \mathrm{mol} / 1$ (range $0.6-4.4 \mu \mathrm{mol} / \mathrm{l}$ ).

Nielsen et al also could not show effects on nerve conduction velocities. ${ }^{4}$ In the study of Rosén and coworkers, ${ }^{12}$ no correlation between vibratory perception and $\mathrm{B}-\mathrm{Pb}$ concentration was found, whereas there was a slight correlation between the $\mathrm{B}-\mathrm{Pb}$ concentration and peroneal nerve motor conduction velocity, as well as the median and sural nerve sensory conduction velocity and amplitude. In this study, mean $\mathrm{B}-\mathrm{Pb}$ measurements over one year were used in calculations.

The present results are considerably different from those previously published. This is explained by the differences in the study design. The body- $\mathrm{Pb}$ was more reliably estimated than in the previous studies. The current $\mathrm{B}-\mathrm{Pb}$ concentration did not correlate with conduction velocity results but showed a correlation with the vibration thresholds; the highest correlation was found with that of the finger, with the limits method. With integrative $\mathrm{B}-\mathrm{Pb}$ concentrations, an association with past exposure and vibratory perception could be shown. Another explanation may be that the differences in the design of the measuring devicefor example, the stability of the vibrating head, the weight of the head, and its inclination on the limb-explain the sensitivity differences.

In the conduction velocity studies, a decrease of the sensory amplitudes was associated with the exposure to lead. The effect was weaker than in the case of the vibratory thresholds, but the trend was obvious. The decrease of the sensory amplitudes has been described previously. ${ }^{25-27}$ The decrease in sensory amplitude is usually thought to be caused by axonal degeneration, even though a partial conduction block can also lower the amplitude of the response. Denervation changes and increase in distal motor latency of the median nerve have been described in a group of lead workers with variable exposure. ${ }^{28}$ In experimental work, exposure to lead results in damage to the myelin sheath in most animal species, leading primarily to slowing of the conduction velocity. There are, however, significant differences between species - for example, rabbits have an axonal degeneration as the most prominent effect. In cases of clinical lead poisoning, both damage of the myelin sheath and axonal degeneration have been described. ${ }^{29}$

The parallel changes of psychological performance and peripheral nerve function are interesting. A suggestive connection was found between the poorest performance in psychological tests and increased vibratory thresholds. When considering the link, it may be noted that the vibratory perception is not 
purely a peripheral sensation. A significant part of its perception occurs in the central nervous system, even though its changes are usually most obvious in diseases of the peripheral nervous system. ${ }^{30}$ The parallelism in the effects suggests a substantial association with exposure to lead.

\section{QUANTITATIVE EEG}

Conventional, visually interpreted paper EEGs are usually normal in occupationally exposed workers, if people with symptomatic intoxications are excluded. ${ }^{31}$ Burchfield and co-workers ${ }^{32}$ found that children with high concentrations of lead in their teeth had increased amounts of low frequency delta activity over central, parietal, and occipital cortices, and decreased amounts of alpha activity over parietal and occipital regions. An increase of coherence in all frequency bands of the quantitative EEG has been found even in children with $\mathrm{B}-\mathrm{Pb}$ concentrations $<15 \mu \mathrm{g} / \mathrm{dl}$ $(0.7 \mu \mathrm{mol} / \mathrm{l}) .^{33}$ These results cannot, however, be compared with ours, because the brains of children may react to noxious factors differently from the brains of adults.

The changes in quantitative EEG found in the present study differ from those caused by cerebral diseases. Damage to the cerebral tissue typically causes an increase in the slow and a decrease in the fast activity of the EEG. Tranquillisers and hypnotic drugs cause an increase in the amount of beta activity, but alpha activity usually either decreases or remains unchanged. Short episodes of very shallow drowsiness occur during the state of wakefulness. ${ }^{34}$ During this transitional state between wakefulness and drowsiness, activity in the alpha band increases in the frontal and central areas, this alpha activity being slower than the alpha activity present in wakefulness. This phenomenon can be the first sign of emerging drowsiness. ${ }^{3435}$ Thus the positive correlation between slow alpha activity and measures of body- $\mathrm{Pb}$ could indicate increased episodes of "microdrowsiness" in subjects with higher exposure to lead. If this is true, it would mean that the possibility of increased day time tiredness should be taken into account in long standing lead workers.

\section{Conclusions}

After long term exposure (median 17 years) to low concentrations of lead (medians of mean and maximal $\mathrm{B}-\mathrm{Pb}$ concentrations, 1.5 and 2.4 $\mu \mathrm{mol} / 1)$, only minor effects were found on nerve conduction velocities, whereas an effect was found on the sensory amplitude of the sural nerve. During the past three years, the exposure was even lower (medians of mean and maximal $\mathrm{B}-\mathrm{Pb}$ concentrations, 1.4 and 1.7 $\mu \mathrm{mol} / \mathrm{l})$; this exposure was not related to decreased conduction velocities nor sensory amplitudes. Vibratory thresholds of the upper limb, especially of the finger, were clearly related to these recent exposures to lead, and those of the lower extremity (medial malleolus), to the long term exposure. Quantitative EEGs also proved to be a sensitive tool for the assessment of subtle effects of lead. Changes in the absolute and relative power as well as mean frequency of different EEG channels were found to be mainly related to long term exposure to lead. Neurophysiological effects of lead had the closest relations with a history of $\mathrm{B}-\mathrm{Pb}$, but also to some extent with body- $\mathrm{Pb}$, as assessed from calcaneal and tibial lead concentrations.

1 Seppäläinen A-M, Hernberg S. Sensitive technique for detecting subclinical lead neuropathy. $\mathrm{Br} F$ Ind $\mathrm{Med}$ 1972;29:443-9.

2 Seppäläinen AM, Tola S, Hernberg S, Kock B. Subclinical neuropathy at "safe" levels of lead exposure. Arch Environ Health 1975;30:180-3.

3 Seppäläinen AM, Hernberg S. Subclinical lead neuropathy. Am 7 Ind Med 1980;1:413-20.

4 Nielsen CJ, Nielsen VK, Kirkby H, Gyntelberg F. Absence of peripheral neuropathy in long-term lead-exposed subjects. Acta Neurol Scand 1982;65:241-7.

5 Triebig G, Weltle D, Valentin H. Investigations on neurotoxicity of chemical substances at the workplace. $V$. Determination of the motor and sensory nerve connduction velocity in persons occupationally exposed to lead. In Arch Occup Environ Health 1984;53:189-204.

6 Somervaille LJ, Chettle DR, Scott MC. In vivo measurement of lead in bone using $\mathrm{x}$-ray fluorescence. Phys Med Biol 1985;30:929-43.

7 Chettle DR, Scott M, Somervaille LJ. Improvements in the precision of in vivo bone lead measurements. Phys Med Biol precision of in vivo

8 Erkkilä J, Armstrong R, Riihimäki V, Chettle DR, Paakkari $\mathrm{A}, \mathrm{Scott} \mathrm{M}$, et al. In vivo measurements of lead in bone at four anatomical sites: long term occupational and consequent endogenous exposure. $\mathrm{Br} \mathcal{F}$ Ind $M e d$ 1992;49:631-

9 Aaserud O, Juntunen J, Matikainen E. Vibration sensitivity thresholds: methodological considerations. Acta Neurol Scand 1990;82:277-83.

10 Araki S, Honma T. Relationships between lead absorption and peripheral nerve conduction velocities in lead workers. Scand F Work Environ Health 1976;2:225-31.

11 Seppäläinen AM, Hernberg S, Kock B. Relationship between blood lead levels and nerve conduction velocities Neurotoxicology 1979;1:313-32.

12 Rosén I, Wildt K, Gullberg B, Berlin M. Neurophysiological effects of lead exposure. Scand $¥$ Work Environ Health 1983, 9:431-41.

13 He F, Zhang S, Li G, Zhang S, Huang J, Wu Y. An electroneurographic assessment of subclinical lead neurotoxicity. Int Arch Occup Environ Health 1988;61:141-6.

14 Discalzi G, Fabbro D, Meliga F, Mocellini A, Capellaro F Effects of occupational exposure to mercury and lead on brainstem auditory evoked potentials. Int $\mathcal{F}$ Psychophysiol 1993;14:21-5.

15 Kajiyama K, Doi R, Sawada J, Hashimoto K, Hazama T, Nakata S, et al. Significance of subclinical entrapment of nerves in lead neuropathy. Environ Res 1993;60:248-53.

16 Matsumoto T, Fukaya Y, Yoshitomi S, Arafuka M, Kubo N, Ohno Y. Relations between lead exposure and peripheral neuromuscular functions of lead-exposed workers neuromuscular functions of lead-exposed workers

17 Araki S, Murata K, Uchida E, Aono H, Ozawa H. Radial and median nerve conduction velocities in workers exposed to lead, copper, and zinc - a follow-up study for two years Environ Res 1993;61:308-16.

18 Murata K, Araki S, Yokoyama K, Uchida E, Fujimura Y Assessment of central, peripheral, and autonomic nervous system functions in lead workers - neuroelectrophysiological studies. Environ Res 1993;61:323-36.

19 Sata F, Araki S, Murata K, Fujimura Y, Uchida E. Are faster or slower large myelinated nerve fibers more sensitive to chronic lead exposure - a study of the distribution of conduction velocities. Environ Res 1993;62:333-8.

20 Lille F, Margules S, Fournier E, Dally S, Garnier R. Effects of occupational lead exposure on motor and somatosensory of occupational lead exposure on motor and somatosen.

21 Abbate C, Buceti R, Munaò F, Giorgianni C, Ferreri G. Neurotoxicity induced by lead levels: an electrophysiological study. Int Arch Occup Environ Health 1995;66:389-92.

22 Ehle A. Lead neuropathy and electrophysiological studies in Ehle A. Lead neuropathy and electrophysiological studies in
low level lead exposure: a critical review. Neurotoxicology low level lead expo
1986;7:203-16.

23 Landrigan PJ. Current issues in the epidemiology and toxicology of occupational exposure to lead. Environ Health Perspect 1990;89:61-6.

24 Landrigan PJ. Strategies for epidemiologic studies of lead in bone in occupationally exposed populations. Environ Health Perspect 1991;91:81-6.

25 Bordo B, Massetto N, Musicco M, Filippini G, Boeri R Electrophysiological changes in workers with "low" blood lead levels. Am f Ind Med 1982;3:23-32.

26 Baker EL, Feldman RG, White RA, Harley JP, Niles CA Dinse GE, Berkey CS. Occupational lead neurotoxicity: behavioural and electrophysiolorical evaluation Study design and year one results. Br F Ind Med 1984;41:352-61. 
27 Murata K, Araki S, Aono H. Effects of lead, zinc, and copper absorption on peripheral nerve conduction in metal workers. Int Arch Occup Environ Health 1987;59:11-20.

28 Yeh JH, Chang YC, Wang JD. Combined electroneurographic and electromyographic studies in lead workers. Occup Environ Med 1995;52:415-9.

29 Beritic T. Lead neuropathy. Crit Rev Toxicol 1984;12:149213.

30 Halonen P, Halonen J-P, Lang HA, Karskela V. Vibratory perception thresholds in shipyard workers exposed to solvents. Acta Neurol Scand 1986;73:561-5.

31 Jeyaratnam J, Devathasan G, Ong CN, Phoon WO, Wong PK. Neurophysiological studies on workers exposed to lead. $\mathrm{Br}$ f Ind Med 1985;42:173-7.
32 Burchfield JL, Duffy FH, Bartels PH, Needleman HL. The combined discriminating power of quantitative electroencephalography and neurophysiological measures in evaluting nervous system efrects of lead at low levels. In Needleman HL, ed. Low level lead exposure: the clinical implications of current research. New York: Raven Press, 1980:75-89.

33 Benignus VA, Otto DA, Muller KE, Seiple KJ. Effects of age and body lead burden on CNS functioning in young children II. EEG spectra. Electroencephalogr Clin Neurophysiol 1981;52:240-8.

34 Santamaria J, Chiappa KH. The EEG drowsiness in normal adults. $\mathcal{F}$ Clin Neurophysiol 1987;4:327-82.

35 Kojima T, Shimanozo Y, Ichise K, Atsumi Y, Ando H, Auto $\mathrm{K}$. Eye movement as an indicator of brain function. Folia Psychiatrica et Neurologica faponica 1981;35:425-36.

\section{Occupational and Environmental Medicine and the electronic age}

OEM has an Email address which is 100632.3615@compuserve.com. We welcome contact by Email, including letters to the editor. Some of our reviewers already send us their reports by Email, helping to speed up the peer review process.
Our publishing system is now fully electronic, and authors are sending their revised copy to us on disk as well as paper. Watch for revised Instructions to Authors.

The Editor 